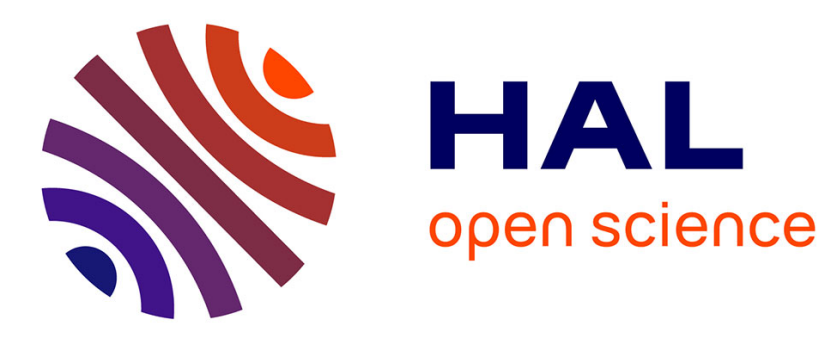

\title{
The Chinese names of the four directions
}

Laurent Sagart

\section{To cite this version:}

Laurent Sagart. The Chinese names of the four directions. Journal of the American Oriental Society, 2004, 124 (1), pp.69-76. halshs-00087314

\section{HAL Id: halshs-00087314 https://shs.hal.science/halshs-00087314}

Submitted on 22 Jul 2006

HAL is a multi-disciplinary open access archive for the deposit and dissemination of scientific research documents, whether they are published or not. The documents may come from teaching and research institutions in France or abroad, or from public or private research centers.
L'archive ouverte pluridisciplinaire HAL, est destinée au dépôt et à la diffusion de documents scientifiques de niveau recherche, publiés ou non, émanant des établissements d'enseignement et de recherche français ou étrangers, des laboratoires publics ou privés. 


\title{
The Chinese names of the four directions ${ }^{1}$
}

\section{Laurent SAGART}

\author{
CNRS, Paris
}

\begin{abstract}
It is shown that the Old Chinese terms for the four directions: 東 'east', 西 'west', 南 'south' and 北 'north', form two etymological pairs, one of which (northsouth) relates to the notions of front and back (of the house: houses faced south in early China ) and the other (east-west) to notions of beginning vs. ceasing movement, applied to the sun. The relevant word families are adumbrated, the morphology explained and Sino-Tibetan cognates established.
\end{abstract}




\section{Introduction}

The Chinese characters for the four directions: 東 'east', 西 'west', 南 'south' and 北 'north' are attested in the epigrapy from the Shang inscriptions (ca. 1400-1100 BCE) onward. The corresponding words in reconstructed Middle Chinese (based on the rhyme dictionary Qie Yun, ca. 600 CE; transcribed here in Baxter's Middle Chinese notation, see Baxter 1992) were *tuwng, *sej, *nom, "pok. Other SinoTibetan languages use different terms for the same notions, hence these four terms are probably Chinese innovations. Here I use the framework presented in Sagart (1999) to discuss their etymology. In that work, I proposed that Old Chinese words consist of a root (consisting of a consonant, plus a vowel, plus an optional second consonant, and an optional glottal stop: $\operatorname{CV}(C)(?))$, and various affixes (prefixes, suffixes, an infix), each of which had specific grammatical or lexical functions. Words with the same root but different affixes have related meanings and similar pronunciations: they form a Chinese word family. One should also keep in mind that Chinese is a Sino-Tibetan language, ${ }^{2}$ and that evidence for both the roots and the affixes under discussion may be found in languages like Tibetan or Burmese. 
Since semantic change tends to follow very similar paths across languages, it will serve us first to review the most common etymologies of the terms for the four directions in the Indo-European languages:

"The majority of words for the main points of the compass are based either on the position of the sun at a given time of day ('sunrise, dawn, morning' = 'east', 'sunset, evening' = 'west'; 'midday' = 'south'), or on one's orientation, which among the Indo-European-speaking peoples was usually facing the sunrise ('in front' = 'east'; 'behind' = 'west'; 'right' = 'south'; 'left' = 'north'), though there are also traces of orientation towards the north or south (the latter in the Avesta, where 'in front' = 'south'; 'behind' = 'north')".

(Carl D. Buck, 1949:870-871)

The glosses in the Shuo Wen Jie Zi 說文解字(ca. 100 CE) for 東 *tuwng 'east' and 北 *pok 'north' suggest etymologies along the same lines as those indicated by Buck for Indo-European. The Shuo Wen relates 東 *tuwng to 動 *duwngX 'move' and 北 *pok 'north' to 背 *pojH 'the back' respectively. Especially in the last term, 
one recognizes a close analog of the designation of the west in Irish, Church

Slavonic and Sanskrit, which in these languages is derived from a word meaning 'behind' (Irish iarthar 'west' < iar- 'behind'). That a word for 'behind' acquires the meaning 'west' in an Indo-European language is not surprising, since, as Buck indicates, the direction of reference ('the front') in the Indo-European world was the east. ${ }^{3}$ In Chinese on the contrary, the direction of reference is more likely the south, as suggested by these clues:

- Chinese compasses conventionally point to the south, as the name 指南針 indicates, rather than to the north;

- traditional Chinese maps place the south at the top, 'in front' of the reader;

- the terms 右 'right' and 左 'left' are used for the west and east respectively in some geographical terms (such as 江 左 for 江 東 and 江右 for 江西).

Admittedly, these facts relate to much later periods, but in the absence of conflicting evidence from early historical times, the simplest hypothesis is that the south was already the direction of reference in early China. 
In the following sections, I turn to each of the Chinese terms for the four directions.

In an earlier work (Sagart 1988), I discussed the etymology of 南 'south' and 北

'north'. I have little of substance to add today to the conclusions of that paper. I will first summarize these conclusions in sections 2 and 3 , reformulating them in the terms of the 'roots and affixes' framework in Sagart (1999), and adding detail where necessary. Then, in sections 4 and 5 , which form the core of this paper, I will investigate the etymology of 西 'west' and 東 'east'.

\section{North}

The origin of the word for 'north' is quite transparent. The difference in pronunciation between 北 'north', Middle Chinese *pok, and 背 'the back', Middle Chinese *pojH, is due to morphology: both words are based on an Old Chinese verb root *apik 'to turn the back', evolving regularly to Middle Chinese *pok 'north' (the direction one turns the back on) on the one hand, and to a body-part noun derived by means of the nominalizing -s suffix *apłk-s, to Middle Chinese *pojH 'the back' on the other hand.

3. South 
In Sagart (1988), I argued that *nom 南 'south' is based on an Old Chinese root ${ }^{*}$ nim designating the belly or front part or the body. That root occurs in the verbs 妊 and 任, both from Old Chinese *bnim. The first means 'to be pregnant', which can be understood as 'to carry inside the belly': the second means 'to carry a burden', especially on the front of the body. ${ }^{4}$ Note also Cantonese naam 4 腩 'belly (esp. of an ox)', from Old Chinese *nim?. The term *nom 南 'south', from an earlier notion of 'front of the body', is then symmetrical in its etymology to 北, from 'back of the body'. In the same work, I proposed that the character 南 itself is a drawing of the front of a house. Compare in fig. 1 below some representative Shang exemplars of 南 (top row, marked 'a') and of radical 40 ("寶蓋頭"), once an independent character meaning 'roof' (bottom row, marked 'b'):

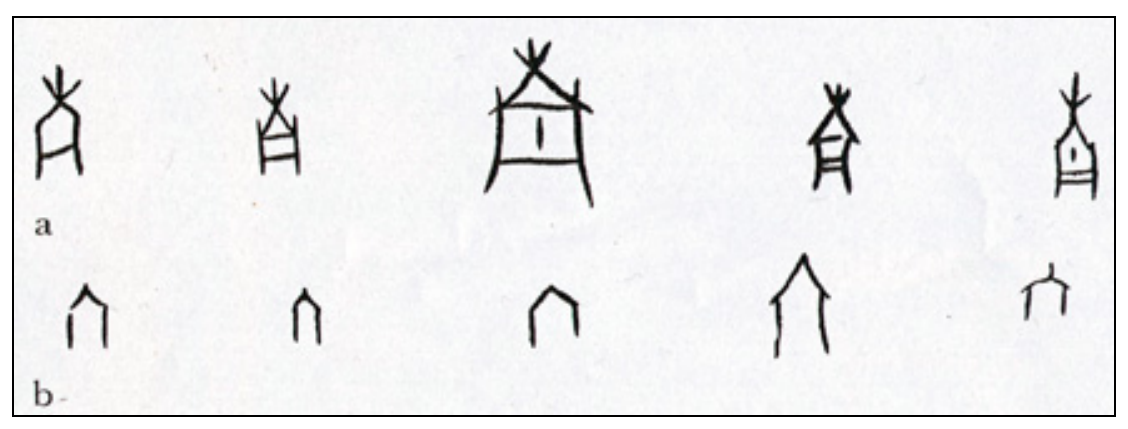

Figure 1: the graphs for 南 (a) and radical 40 (b) in the Shang inscriptions (source: Zhongguo Kexueyuan Kaogu Yanjiusuo (1965: 273-274, 315). 
The Shang graphs for radical 40 (bottom row) show a simple building structure with roof. The graphs in 1a (top row) are similar in their general shape, but the added detail (the three-pronged element at the top; 5 the horizontal and vertical strokes inside the main frame) could represent architectural details, such as openings, characteristic of the front of houses. A picture of the front of a house would have been evocative of the south to the early Chinese, for the reason that, at least in the Anyang region, Chinese houses were commonly built facing south in antiquity, as shown by the excavations at Xiaotun (Chang Kwang-chih 1977:246). This architectural trait aimed at minimizing loss of heat in winter: it is still prevalent in rural north China. I would suggest that the south became the direction of reference in Chinese culture precisely as a result of that architectural custom.

I should add that a Sino-Tibetan cognate of the Chinese word for 'south' can now be cited: the form *nam 'ribs, chest, breast, sides of the body', reconstructed by Benedict (1972) for his Proto-Tibeto-Burman, corresponds regularly to the Old Chinese root "nim 'front of the body'. There exists a well-known tendency among body-part terms to shift their meaning from one part of the body to another which is 
next to it: semantic interchange between 'belly', 'chest' and 'breast', between 'chest' and 'ribs', and between 'ribs' and 'sides of the body', is commonplace. I consider Benedict's *nam 'ribs etc.' to be the true cognate of Old Chinese *abnim 'front of the body', and, further, of 南 'south'. Benedict's own view of the etymology of 南 'south' is different: he relates it to a Sino-Tibetan word "nam 'sun, sky'.

Phonetically Benedict's proposal and my proposal to relate 南 to *nam 'rib, chest, breast, etc.' are equivalent. Semantically, Benedict's finds some support from other languages (such as English) where the word for 'south' is related to the word for 'sun'. Had I only the word 南 to consider, I might have preferred Benedict's interpretation. What leads me to think that mine is preferable is that it provides a unified account of the Chinese terms for 'north' and 'south', by treating them as a pair of antonyms: front and back of the body or the house; while Benedict's only accounts for 'south'. Moreover, that the early graph for 'south' appears to represent the front of a house suggests that the notions of 'front' and 'south' were semantically related in the mind of the early Chinese.

4. West 
The Shuo Wen Jie Zi explains the graph for 西 'west' as a drawing of a bird's nest, comparing the sun at the end of the day to a bird returning to its nest. Far-fetched though it may seem at first sight, this explanation is in fact probably valid: first, there existed in Old Chinese a word 棲, Middle Chinese *sej (homophonous with 西), meaning 'bird's nest; to roost, rest'. Allan (1991) has argued that in early Chinese cosmogony the sun roosted in a tree in the western side of the world after crossing the sky. Second, the idea of resting or 'ceasing motion' is symmetrical of the idea of 'setting into motion', which we found in the verb 動, especially in the expression 動身. We should therefore look for an Old Chinese root meaning 'rest, to rest, cease motion' in *sej 西 'west'. Problems here have to do with (1) identifying and reconstructing the root; (2) explaining its morphology, and (3) identifying SinoTibetan cognates.

Specialists have mostly reconstructed 西 with initial s- in Old Chinese: Karlgren *siar, Li Fang-kuei *sid, Baxter *sijj, etc. Unger (1990:90) departs from this trend, reconstructing an initial consonant cluster sn-, based on the observation that the archaic graphic variant 迺 of the character 乃 *ani? 'then' includes 西 as phonetic. Unger's proposal is convincing, despite the partial difference in rhymes between 西 
and 逎: indeed there seems to be no other explanation for the inclusion of 西 in 逎.

The evolution from Old Chinese *s-n- to MC s- is regular: for more examples see Sagart (1999: 65, 66, 69). Moreover, reconstructing an ${ }^{*} n$ as the root initial of 西 solves an additional problem: one character in which 西 occurs as phonetic: 哂 'to smile', has initial sy- in Middle Chinese: but while Middle Chinese sy- nevercomes from Old Chinese s-, it is the regular outcome of Old Chinese bhn-. If 哂 'to smile' had initial bhn- in Old Chinese, the choice of 西 as a phonetic in the character for this word makes excellent sense.

The reconstruction of the rhyme as $-\mathrm{ij}$ by Baxter follows from two facts: first, the Middle Chinese pronunciation is sej, where -ej is a regular outcome of Old Chinese -ij; and second, from the fact that in the Odes 西 rhymes (once) with 隮, Old Chinese *tsij (Baxter). This is in an internal rhyme in the second stanza of Ode 51 蝃蝀 $\mathrm{Di}_{4}$-dong ${ }_{1}$ (Yong Feng: that ode is further discussed below in connection with 東, also a rhyme word in that same ode). However, Baxter's -ij does not account for the fact that a number of characters in which 西 is phonetic end in - $n$ in Middle Chinese pronunciation: for instance 酒 'to wash', Middle Chinese sejX and senX (two readings), also 哂 'to smile', already discussed in connection with the initial, 
Middle Chinese syinX. Vacillation between Middle Chinese $-j$ and $-n$ is characteristic of words ending in Old Chinese *-r and/or *-I.6 These Middle Chinese - $n$ endings would be hard to explain if 西 had ended in $-j$ in Old Chinese. We should, therefore, reconstruct *-I or *-r. Note that Tibetan has b-sil 'to wash' corresponding to 酒 'to wash'. The lack of initial n- in the Tibetan word suggests 酒 never had root-initial n- either. Why, then, was it written with 西 as phonetic? in all likelihood, the character 酒 was used in the meaning 'to wash' only after 西 had changed from asn- to s-.

In my system of Old Chinese reconstruction (Sagart 1999), Unger's reanalysis of the initial and my reinterpretation of the rhyme lead to Old Chinese ${ }^{*}$ s-nil (the choice of *-il over *-ir is arbitrary), where s- is a prefix and *anil is the root. There is some collateral evidence for a Chinese root *abnil 'to rest, stop': a word pronounced as Middle Chinese nrij (女夷切), written as 尼, occurs in some Late Archaic or Middle Chinese lexica, with the following related meanings:

- 'rest, to rest' <<尼, 息也>> (五音集韻);

- 'peace, peaceful' (=at rest) $<<$ 尼，安也>> (廣雅釋詁一); 
- 'harmony, harmonious' (=at peace with one another) <<尼，和也>> (廣韻);

- 'to fix'<<尼, 定也>> (爾雅釋詁. Guo Pu 郭璞 comments: <<尼者止也, 止亦定 >> '尼 means "to stop", which also means "to fix" ').

This word, Middle Chinese nrij, is a possible outcome of Old Chinese ${ }^{*}$ bnril, although it could also reflect Old Chinese *bnrij. Old Chinese *bnril consists of root ${ }^{*}$ bnil plus infix -r-. In Sagart (1999) I have characterized the functions of the -r- infix in verbs as (1) repeated action; (2) action taking place in two ro more locations or involving a collective participant. Here -r- takes the second function: the meanings 'peace, peaceful' and especially 'harmonious' involve a collective participant. Peace and harmony may be described as a number of individuals at rest with one another.

A second set of forms have Shangsheng in Middle Chinese, arguing for an Old Chinese root *abnil? 'to stop', with final glottal stop. This root, of course, is closely related to the precedent, but the meaning 'to rest' is not prominent in it. A first form occurs in the Lun Yu (論語，子張 4, p. 341 in Legge's The Chinese Classics Vol. 1, Southern Materials Center reprint, 1985), written as 泥, in the meaning 'impeded, obstructed' (不通也): 


\begin{abstract}
子夏日，雖小道必有可觀者焉，致遠恐泥.
"Even in inferior studies and employments there is something worth being looked at; but if it be attempted to carry them out to what is remote, there is a danger of them proving inapplicable" (Legge's translation)
\end{abstract}

The Jing Dian Shi Wen 經典釋文 gives the reading nejH, in qusheng, for this particular occurrence of 泥, which is compatible with a number of Old Chinese sources. The situation is clarified by the Ji Yun 集韻 reading nejX (乃禮切) for 泥 in the meaning 不通也, indicating Old Chinese ${ }^{*}$ anil? (but ${ }^{*}$ anij? is also possible). This gives us cause to reconstruct ${ }^{*}$ anil2-s for the reading nejH assigned by the Jing Dian Shi Wen to 泥 in this passage from the Lun Yu.

A second form is 柅 'stopper for carriage wheels', Middle Chinese nrijX, possibly the outcome of Old Chinese ${ }^{*}$ nritl? (or *anrij?), with infixed -r-. In Sagart (1999:115) I have characterized the infixed -r- in nouns as marking 'name(s) of double or multiple objects'. I suppose that a 柅 was double in the sense that it blocked both wheels of a carriage, although this is speculative. 
We have a text example of 尼 used in the sense of 'to obstruct, stop' in Meng Zi(梁 惠王下 16.3, p. 179 in Legge's The Chinese Classics Vol. 2, Southern Materials Center reprint, 1985):

行或使之，止或尼之

"A man's advancement is effected, it may be, by others, and the stopping him is, it may be, from the efforts of others" (Legge's translation)

The Middle Chinese reading traditionally associated with this particular occurrence of 尼 is surprising: nrit (女乙反) according to the Jing Dian Shi Wen 經典釋文, with final -t. This form cannot be related to either of our two roots *nil 'to stop, rest' and "nill? 'to stop' by using the apparatus in Sagart (1999); a suffix -t would be required. Chinese-internal evidence for a suffix -t with a specific function, so far, has been quite inconclusive, but other Sino-Tibetan languages (like Kachin or the Kiranti languages) have a suffix -t which turns an intransitive verb into a transitive one (Benedict 1972:101). This function fits very well with our Meng Zi example, where 尼 certainly writes a transitive verb. If this observation is meaningful, this is the first 
solid case of alternation between an intransitive verb without -t and a transitive verb with -t documented in Chinese.

There remains to explain the function of the s- prefix in 西. It is, I believe, the verb nominalizer prefix described in Sagart (1999: 73): under that analysis 西 *as-nij is to be understood as 'the place where [the sun] rests', just like 樹 *bs-m-lak-s is 'the place where one shoots with bow and arrow' (from 射 *bm-lak-s 'to shoot with bow and arrow').

The meaning 'rest, stop', which can be assigned to root " $\mathrm{nil}$, is a good counterpart to the meaning 'start moving', which the Shuo Wen tells us underlies 東 'east'.

There is, therefore, a likelihood that 東 'east' and 西 'west' form a pair of antonyms: 'to start moving' vs. 'stop moving, rest', just like 南 'south' and 北 'north' are 'front of the body' vs. 'back of the body'.

Finally, we need to identify cognates of this Chinese root in other Sino-Tibetan languages. Semantically the clearest cognate is certainly Burmese nâ 'to cease from motion or action through desire for rest; to perch, as a bird', to which 
corresponds Tibetan rnal 'rest'.7 The sound correspondences ST -ə-: Old Ch. -i-, Tib. -a-, Burm. -a-, on the one hand; and ST -l: Old Ch. -l, Tib. -l, Burm. -zero, on the other hand, are regular (see Gong 1980,1995$)$. Thus we may suppose a proto-form something like *nəl 'rest, cease motion, alight' in the ancestral language of Chinese, Tibetan and Burmese. From this *nəl both 尼 'to stop' *bnril (with infixed -r-, collective) and 西 'west' as-nil (with prefixed s-, nominalizing) arose.

\section{East}

The Shuo Wen defines 東 *tuwng 'east' with the verb 動, Middle Chinese *duwngX 'to move'. Unlike 西, 東 is a frequent rhyme word in the Odes, with 15 occurrences (for the complete list, see Baxter 1992:754). In fully 14 of these, 東 rhymes with -on words, but in one case -in the very same ode where 西 occurs as a rhyme: ode 51 䖢䗲 $\mathrm{Di}_{4}$-dong ${ }_{1-}$, 東 rhymes with a shangsheng syllable: 蝀 aton? (this will be discussed below). Although Karlgren assigned 東 and 動 to two different phonetic series, in the oracular script the graph for 動 includes the graph for 東, apparently as a phonetic. On the phonetic side, there are, then, two points to elucidate: (a) why do 東 and 動 have different initials, t- and d-, in Middle Chinese ? and (b) why 
do they have different tones -tone Shang, noted by Baxter's -X in 動, against tone

\section{Ping in 東- ?}

Concerning the first question, I have shown (Sagart 1999) that the Middle Chinese voiced stop and affricate initials (b-, d-, g-, dz- etc.) have at times evolved out of Old Chinese voiceless initials preceded by a nasal prefix, so that Old Chinese *Np-, *Nt-, *Nk-, Nts- (where ' $\mathrm{N}$ ' is a nasal prefix) regularly evolve to Middle Chinese b-, d-, g-, dz-. If we supposed a nasal prefix in the Old Chinese precursor of Middle Chinese 動 *duwngX, this would solve the problem of the initials: we could assume that the two words are built on the same root, probably a verb meaning 'to start moving', with root initial t-, which in the case of 動 changed to d- in Middle Chinese under the influence of the nasal prefix.

In Sagart (1999: 80) I identified one nasal prefix capable of voicing a following voiceless initial: prefix $\mathrm{N}$-, which changed a transitive verb into its intransitive counterpart. Unfortunately, that is not the case here, as 動 has both transitive and intransitive uses, always with initial d- in Middle Chinese: the intransitive N- prefix cannot solve the problem. I had in the same work identified a second nasal prefix: 
${ }^{*} \mathrm{~m}$-, which marks verbs of voluntary action, but examples of $\mathrm{m}$ - preceding voiceless stop and affricate initials were missing. I have now collected some examples: they indicate that, like $\mathrm{N}$-, prefixed $\mathrm{m}$ - also changes a voiceless stop or affricate into a voiced one. An example is:

覺 *akruk > kaewk 'to awake, apprehend, get insight' (involuntary) ; vs. 學 *am-kruk $>$ gaewk > haewk 'to study, imitate' (voluntary).

In all the early text examples I have been able to examine, 動 occurs with animate subjects. This is of course because only animate subjects have volition. This, then, is an indication that 動 was a volitional verb. It is possible, therefore, that it carried the volitional m- prefix. In contrast, the movement of the sun is predictable and involuntary. Prefixed $\mathrm{m}$ - is excluded in a verb denoting the movement of the sun across the sky. I therefore reconstruct on the one hand 動 *am-tong? > duwngX 'to start moving' (voluntary), and on the other hand *atong?, 'to start moving', used of inanimate and non-volitional subjects such as the sun. I suppose the latter reconstruction is the prototype out of which 東 *tuwng 'east' was formed. 
Finally I come to the question of the difference in tone between 動 and 東. The former was MC duwngX (tone Shang, going back to -on? in Old Chinese) while the latter was MC tuwng (tone Ping, going back to -on in Old Chinese). It is well known that words belonging to lists which are recited in a fixed order (such as the numerals from 1 to 10 ; the days of the week; the list of calendar months; etc.) frequently undergo changes such that the pronunciation of one of the words in the list is influenced by one of its immediate neighbors (thus Proto-Austronesian *Siwa 'nine' irregularly changed its initial to s-8 in Proto-Malayo-Polynesian, under the influence of the word for ' 10 ' which began in s-: Blust 1995). It is possible that 東 was pronounced as *atong? in early Old Chinese, and that it lost its final -? ( (the Old Chinese source of the Middle Chinese Shang tone) under the influence of 西 and 南, which follow it immediately in the list of directional terms, and are both without final - - . Indeed, as mentioned earlier, we have one instance of 東 rhyming 'irregularly' with the Shangsheng syllable 蝀 aton? in an internal rhyme in the first line of the first stanza of Ode 51 (translations are from Karlgren 1944):

\section{蝃蝀在東}

'the rainbow is in the East' 
In the present interpretation, this would be an archaism, with 東 occurring in its etymological shangsheng reading. One notes that the first line of the second stanza also has an internal rhyme between the second character 隮 (Baxter tsij) and the fourth character 西 (Baxter sij):

\section{朝隮于西}

'at dawn there are rising vapours in the west'

The parallel construction of the first lines of the first and second stanzas indicates that the internal rhyme between 蝀 and 東 in the first stanza is intentional.

This explanation for the change of tone in 東 relies on the hypothesis of an analogical sound change: it is therefore difficult to verify or disprove. At least it is a verifiable fact that the terms for the four direction form a fixed-order list, and that 東 is followed by two words in tone Ping in both known variants of that list. ${ }^{9}$ 
It is interesting to consider the graphic history of the character 東. In the oracular script it appears to have been the drawing of a bundle-like object. ${ }^{10}$ Reanalysis of this graph as a combination of 日 'sun' and 木 'tree' (quite similar-looking, in the bronze script) was already accomplished in the small seal script. Whatever the reasons, it is worth noting that the 日 'sun' element in the reanalyzed character implies some awareness of a connection to the sun in the term for 'east'.

I will close this discussion of 東 with some words on a claim that Xu Shen 許慎, the author of the Shuo Wen Jie Zi 說文解字, arrived at his gloss 《<東, 動也 >> ('east' is 'to move'), on the basis of the theory of the five agents, which equates 'east' with 'spring' (Bottero 1996:57, relying on earlier scholarship). Under that view, 動 denotes the renewed activity of the myriad beings in the spring, after the torpor of winter: a theory with which, as a Han-time scholar, Xu Shen must have been familiar. The Shuo Wen author would have selected 動 as a gloss for 'east' because 動 was phonetically close to 東, in addition to being indirectly related to the notion of 'east' via the theory of the five agents. This requires a three-stage semantic chain: 'start to move, of the myriad beings' > 'spring' > 'east'. Such a chain, however, is highly indirect, and it is more removed from general human 
experience than the two-stage chain: 'start moving, of the sun' > 'east'. It is highly likely that Xu Shen saw that 東 *atong 'east' could be related semantically to the movements of the sun via the verb 動 *am-tong? ('move, start moving'), and that his gloss reflects that insight, rather than Han-time philosophical theories.

\section{Conclusion}

In this paper I have shown that the explicit 'roots and affixes' framework developed in Sagart (1999) is a powerful tool for explaining the etymology of early Chinese words such as the names of the four directions. Studies such as this not only help us make sense of the words in question, they also help us progress in our understanding of Old Chinese and Sino-Tibetan word-families and morphology.

The Chinese and Indo-European terms for the four directions are parallel in their etymological connections, a fact not due to common history, but pointing unmistakably to the cognitive unity of mankind. Culturally the most salient difference between the two is the southern orientation of the Chinese system, as opposed to the eastern orientation of the Indo-European system. This major 
difference, I have proposed, ultimately results from the early Chinese practice of building south-facing houses.

\section{References}

Allan, S. The Shape of the Turtle, Myth, Art and Cosmos in Early China. Albany:

State University of New York Press, 1991.

Benedict, P. K. Sino-Tibetan: a Conspectus. Cambridge: University Printing House, 1972.

Blust, R. "Sibilant assimilation in Formosan languages and the Proto-Austronesian word for 'nine'." Oceanic Linguistics 34 (1995) 2: 443-453.

Bottero, F. Sémantisme et classification dans l'écriture chinoise. Paris: Institut des Hautes Etudes Chinoises, 1996.

Buck, C. D. A dictionary of selected synonyms in the principal European languages. Chicago: Chicago University Press, 1949.

Chang, K.C. The Archaeology of Ancient China, $3^{\text {rd }}$ edn. Newhaven and London: Yale University Press, 1977. 
Gong, Hwang-cherng. "A comparative study of the Chinese, Tibetan, and Burmese vowel systems." Bulletin of the Institute of History and Philology, Academia Sinica 51 (1980): 455-89.

_ "The system of finals in Sino-Tibetan." in The Ancestry of the Chinese Language, ed. William S.-Y. Wang. Journal of Chinese Linguistics monograph series no. 8, pp. 41-92, 1995.

Karlgren, B. "Grammata Serica (Script and phonetics in Chinese and SinoJapanese)." Bulletin of the Museum of Far Eastern Antiquities 12 (1940).

__ "The book of Odes, Kuo Feng and Siao Ya." Bulletin of the Museum of Far Eastern Antiquities 19 (1944): 171-256.

Matisoff, J. Handbook of Proto-Tibeto-Burman. Berkeley: University of California Press, 2003.

Sagart, L. "Nord et Sud dans la langue des Shang". T'oung Pao LXXIV (1988), fasc. 4-5: 249-54.

_ The Roots of Old Chinese. Current Issues in Linguistic Theory, 184. Amsterdam: John Benjamins, 1999. 
_ "Sino-Tibetan-Austronesian: an updated and improved argument," in The peopling of East Asia: putting together archaeology, linguistics and genetics ed. L. Sagart, R. Blench, A. Sanchez-Mazas. London: RoutledgeCurzon, in press. Unger, U. "Die Armbrust und der steigende Ton." Hao-ku 36 (1990). Zhongguo Kexueyuan Kaogu Yanjiusuo. Jiaguwen Bian. Beijing: Zhonghua, 1965.

1 This is a reworked version of a paper presented at the $3^{\text {rd }}$ Conference of the European Association of Chinese Linguistics in Ghent, September 8-10, 2003 and, in an already modified form, at the roundtable discussion on the concept of space reflected in Chinese Paleography, Paris, March 25-26, 2004. I am grateful to Sarah Allan, William Boltz, Guillaume Jacques, Jiang Shaoyu, Alain Peyraube and Axel Schuessler for useful comments. Errors, of course, are mine.

2 I once considered that Chinese and the Tibeto-Burman did not form a taxon. I have since abandoned that view, see Sagart (in press).

${ }^{3}$ Burmese, a Sino-Tibetan language, has received strong influence from Indic culture. It is therefore not surprising that Burmese uses its words for 'front': hre', and 'back': nok, to refer to the east and west respectively. ${ }^{4}$ See Sagart (1988) note 6. 
5 This three-pronged motif is similar to roof ornaments on buildings depicted in some Warring States bronzes, cf. Figures 2 and 3 in Sagart (1988).

${ }^{6}$ It is uncertain whether Old Chinese had both $-I$ and $-r$ endings, or just one of them.

7 This is preferable to Matisoff's comparison of Burmese nâ with Written Tibetan

gnas-pa 'to live, dwell, stay' (Matisoff 2003:433).

8 Uppercase $\mathrm{S}$ and lowercase $\mathrm{s}$ are different sounds in proto-Austronesian.

${ }^{9}$ Current variants of the list are 'clockwise': 東南西北 and 'paired' 東西南北. There is no known variant of the list in which 東 is immediately preceded or followed by the entering-tone word 北.

10 William. H. Baxter (p.c., July 2004) notes the graphic and phonetic similarity to 束 'bundle', Old Chinese *bs-tok. 